\section{AVOIDING PUBLISHING IN \\ PREDATORY JOURNALS: \\ AN EVALUATION ALGORITHM}

\section{ABSTRACT}

Academics and scholars need to publish their research results. In addition, they are required to publish scientific papers to prove their research commitment and to achieve certain academic titles in higher education institutions. Globally, there are many scientific journals of well-known publishing in academic circles is the increasing number of invitations to publish articles via quick procedures, without going through the adequate review process. This phenomenon is threatening acedures, integrity, as these publishers journals aim at financial benefits and not contributing to scientific development and progress. There is a gap in the knowledge of the scientific researchers regardin the journal selection to publish their work. Some of them are still unintentionally publishing in such journals, mainly as a lack of information about them. The main purpose of this study is awarenessraising, warning, and guidance of scientific researchers, particularly young researchers by providing information on how to avoid submitting manuscripts in these journals. To achieve this, we have information on how to avoid submitting manuscripts in these journals. To achieve this, we have
consulted the recent literature and practices of different countries, summarized the most used tools/methods to identify predatory publishers and journals, and lastly, we have developed a guiding algorithm for evaluating them.

\section{KEYWORDS}

Blacklists, manuscript, open access, predatory journal, predatory publisher, scientific journal, whitelists

\section{HOW TO CITE}

Berisha Qehaja A. (2020) 'Avoiding publishing in predatory journals: An evaluation algorithm', Journal on Efficiency and Responsibility in Education and Science, vol. 13, no. 3, pp. 154-163. http://dx.doi.org/10.7160/eriesj.2020.130305

\section{Highlights}

- Provision of information for recognizing and avoiding publishing in predatory journals.

- The most used tools and methods to identify predatory publishers/journals.

- A proposed algorithm for evaluating publishers/journals.

\section{INTRODUCTION}

cited by Jalalian and Dadkhah, 2015), "dark side of publishing" Advances in contemporary science depend on the distribution (Butler, 2013), "ghost journals" (Menon, 2016). The names of valuable and credible scientific papers, whereas the academic "fake journals" "sham journals" and "pseudojournals" are journal industry depends on a system where competent also used (Berger, 2017). Despite their naming, Laine and academics willingly assess the other scholars "manuscripts. Whiker (2017) emphasize that such journals do not apply the This correction (vetting) process, also known as peer review, peer review process, which is a distinctive feature of scientific highlights the ethical and quality lack in manuscripts. Authors publications.

usually benefit from this process because reviewers make Academic journals have multiplied very rapidly in recent years, recommendations that improve the quality of their manuscripts especially those with open access (hereinafter often referred (Umlauf and Mochizuki, 2018)

The concept of predatory publishing has been widely known has inced too The latter have shown deceitful tendencies,

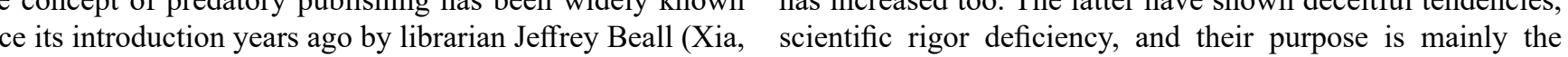
2015). Except "predatory journals" used by Beall (2010), these financial benefit (Kurt, 2018). Umlauf and Mochizuki (2018: journals are known also as "hijacked journals" (Jalalian, 2012; 2 2) describe this phenomenon as follows "This profit-driven scheme bypasses peer review and promises quick publication, but only after the author pays a fee. When a manuscript is poorly written or the science poorly designed, this arrangement
is ideal. On the other hand, honest and mistaken authors who discover their error and seek to withdraw their papess biter discover the

It is considered that predatory journals are the most widely spread category of pseudo journals, and recently they had significant growth (Laine and Winker, 2017). A total of 8,000 active predatory journals published about 420,000 articles in 2014, following a pretty linear increase from 53,000 in 2010 (Shen and Björk, 2015). As stated by Frandsen (2017), possible of journals analogous to the titles of esteemed journals, and the "presence" of academics/scientists from top universities and research institutes. According to Beall (2013: 84) 'there are millions of researchers around the world desperate to publish, and the predatory publishers are eager to have them as customers.

Berger (2017: 206) describes the predatory publishing as 'as low quality, amateurish, and often unethical academic publishing that is usually Open Access (OA),' Wheress, umlauf and Mochizuki (2018) point out that the consequences of publishing in predatory journals for honest researchers are: wasting time, using data in vain, wasted money and manuscripts that end up not being indexed or archived on proper databases. Thus, the identification of these journals is very crucial for writers, scholars, reviewers, and editors, because manuscripts that do not go through the proper review process should not be included in the register of scientific data (Laine and Winker, 2017).

Hereupon, the main purpose of this study is awareness-raising warning, and guidance of scientific researchers, particularly young researchers by providing information on how to avoid manuscript submitting in these journals. Accordingly, the following research tasks have been set:

$$
\text { journals }
$$

- summarizing the most used tools/methods to identify predatory publishers and journals and

developing a guiding algorithm for evaluating publishers and journals.

We believe that this paper will offer significant guidance on avoiding publishing in predatory journals. The paper is organized into five main sections. The first section provides a brief literature review on predatory publishers and journals, their characteristics, open access, article processing charges, and Bohannon's experiment. Then it proceeds with materials and methods of the paper. Further, section three presents results, to continue with discussion in the fourth section. In the and suggestions for future work are given as well.

\section{LITERATURE REVIEW}

Over the past decade, a group of scientific journals has sprea rapidly and has become known as a group of "predatory journals" published by "predatory publishers" (Laine and
Winker, 2017). Subsequently, the research community has

\section{ERIES Journal} volume 13 issue 3 fallen victim to cybercrime. According to Memon (2016: 644), 'this academic pollution had targeted many scientists after the emergence of predatory and hijacked journals.

Xia et al (2015) point out that rarely you can find a scholar who has not received spam e-mails from a fraudulent journal/ conference, which tends to inductee papers/participation. They may also have received emails that invite them to engage in he "peer-review" process or to join the editorial board of particular journal. Whereas according to Greco (2016), scholars who intentionally choose to send their work to predatory journals, particularly those in developing countries, are likely trying to find better work promotion, or research grants (as cited by Umlauf and Mochizuki, 2018)

\section{The open access movement (OA) and article} processing charges (APCs)

Berger (2017: 208) thinks that 'predatory publishing arose from two conditions: the availability of journal publishing platforms and potential revenue from author-paid article al (2017) consider that the OA is more appropriate than the traditional closed-ended publication for the needs and participation in a progressively scientific research community. Also, the peer reviewers from a wider community can often be harsher, replying to the progressively multidisciplinary essence of contemporary study. Moreover, Kurt (2018) explains that the conception of open access has to do with the permitting of research outcomes to be disposable free of charge to all. While open access is an initiative with good intention, however, the essence of its open-source has exacerbated some problems, acilitating the imitation of legitimate journals by predatory journals.

Richtig et al (2018) explain several different APCs models (hereinafter often referred to as APCs). The "gold" open access model (OA) obliges the researcher to spend up to a lot of money to maintain copyright in the work, to guarantee that the content is completely and openly accessible online so that it can be shared with anyone. Then, the "green" OA model constrains the distribution, where researchers can only distribute their papers over a personal website or third-party are as well oher kinds of created 作 for open access to a subscription-based journal. However, epto semscription-based jounals that inpose low taxes ond their work a chen-acess jonnals mist make an additional payment of considerable sum for publication as well, which is named , the predatory publishing model is built on APCs (Berger, 2017). Until 2010 most of the articles were in print versions. Those journals had begun offering their free electronic version. Whereas since 2011 , journals that were only online demanded payment for article processing and grew into the dominant group. Furthermore, the participation of papers in journals based merely online has risen promptly (Björk, 2017). Today, papers and journals can be available online or in hybrid presented by Teixeira da Silva (2015), in 2015 predatory 
publishers published over 500,000 dubious manuscripts (in reviewers may not be named on OA sites, to preserve the 8,000 predatory journals) and generated $\$ 75$ million. That anonymity of the process); c) share information about their same year, legitimate publishers generated $\$ 335$ million in publication fees and explain how these fees are used to support total revenue.

Globally, there are around 20,000 OA journals that claim to be academic and have a peer-review process. Of these, approximately 9,000 are listed in the Directory of Open Access them, specifically the small ones that are published outside of North America and Western Europe and are published in other languages and not in English, are not part of it.

Also according to Shen and Björk (2015), there are about 10,000 doubtful journals published by predatory publishers. These journals have already been removed from the DOAJ list. Whereas, Kozak and Hartley (2013) studied over 9,000 OA journals included in the DOAJ, and proved that only $28 \%$ of them have requested the APCs. On the contrary, the study of Xia (2015) examined OA predatory payments policies, which were listed on scholarlyoa.com at the time. He analyzed 298 predatory journals and compared the number of journals that took APCs (214) with the percentage of those listed in DOAJ. He determined links among the practices of predatory journals and the APCs. This study found that roughly $72 \%$ of predatory considered higher compared to all earlier outcomes.

Bohannon (2013) found that out of a total of 255 articles that were subject to the review process for acceptance or rejection, nearly $60 \%$ of them were accepted without undergoing the rea process of review.

According to Kurt (2018: 144) 'beyond costs and peer review processes, though, there are further points that typically separate legitimate $\mathrm{OA}$ journals from predatory $\mathrm{OA}$ journals, such as the following:

a) legitimate $\mathrm{OA}$ journals are usually (though not always) affiliated with an established scholarly society or academic institution; b) have dedicated editors, editorial staff, and peer reviewers who are also experts in their fields (though peer

the journal; d) usually indexed by multiple scholarly databases, potential authors to access and see whether their work actually meets the publication's subject matter requirements.'

\section{Characteristics of predatory journals}

It is considered that after the publication rate increased and lot of improvements were made in the research field the academic community began to be attacked and to fall victim to cybercrime. This was manifested as ghost journals, fake publishers and magic impact measures (Memon, 2016). Several authors have written about the characteristics of predatory paragraph, we have summarized the detailed characteristics of predatory journals by Berger (2017) and Shamseer et al (2017) (Table 1).

Berger (2017) states that among the main features of predatory journals are: deceitful emails sent to addresses ending in .edu", to invite potential authors for journals/conferences; promises of fast peer review and fast publication; lack of focus on a particular field or very broad field; lack of transparency about author fees; contradictions and inconsistencies; editors are not editors; newness and quantity; copycat names with and nformation that is contradictory or missing; standards and dentifiers missing, stolen or faked; false and fake bibliometrics; fake and unsuitable statements of indexing and presence in databases; amateurish website etc.

(2017) analyzed 93 predatory journals, $99 \mathrm{OA}$ and 100 subscription-based journals (all with biomedical focus) and identified 13 proven characteristics by which predatory journals can be probably differentiated from acknowledged followe journals. These characteristics are presented in the journals charge a fee for processing articles. This finding is and e) outline the scope of their publication on their website for journals. Except those of Kurt (2018) precised in the earlier without copycat websites; author-editor nightmares; location

1. The scope of interest includes non-biomedical subjects alongside biomedical topics 2. The website contains spelling and grammar errors

3. Images are distorted/fuzzy, intended to look like something they are not, or which are unauthorized

4. The homepage language targets authors

5. The Index Copernicus Value is promoted on the website

6. Description of the manuscript handling process is lacking

7. Manuscripts are requested to be submitted via email

8. Rapid publication is promised

9. There is no retraction policy

10. Information on whether and how journal content will be digitally preserved is absent

11. The Article processing/publication charge is very low (e.g., $<\$ 150$ USD)

12. Journals claiming to be open access either retain copyright of published research or fail to mention copyright

13. The contact email address is non-professional and non-journal affiliated (e.g., @gmail.com or @yahoo.com)

Table 1: Salient characteristics of potential predatory journals (Source: Shamseer et al. (2017: 11))
Also, based on the distinctive characteristics of prestigious At the end of 2013, as a reaction to the "Sting," the Open and predatory journals, Rele, Kennedy and, Blas (2017) have Access Scholarly Publishers Association (OASPA) developed This tool provides its "Principles of Transparency and Best Practice in Scholarly

a guide for each listed characteristic and also guides you on Publishing" in cooperation with other crucial players ${ }^{2}$ to journal. Each criterion is evaluated with scores and at the end, the total scores define whether the journal is a proper choice or not for publishing your work. It is worth noting that this tool is easily accessible and usable

Preston (2020) highlights

journals joview Then the following question is rece they perform peer peer review for predatory publishers and journals? To answe this question, according to Preston (2020), Publons has been cooperating with the Swiss National Science Foundation a paper which purposes to examine whether there are patterns to a paper which purposes characteristics for predatory journals, and how reviews for potentially predatory journals are globally distributed.

Hereupon, Severin et al. (2020: 2): 'matched 183,743 unique Publons reviews that were claimed by 19,598 reviewers.' The study results shed light that: '6,077 reviews were conducted for 1160 unique predatory journals (3.31\% of all reviews). 177,666 were claimed for 6,403 legitimate journals $(96.69 \%$ of all reviews). The vast majority of scholars either never or only occasionally submitted reviews for predatory journals to Publons ( $89.96 \%$ and $7.55 \%$ of all reviewers, respectively).' Also, they found that developing regions have a larger share of reviews for predatory journals than developed regions. In addition, the characteristics of scholars who perform the review for potentially predatory journals are similar to those of authors who publish their work in these outlets.

\section{Bohannon's experiment}

A journalist John Bohannon conducted a sting operation to 304 OA publishers. Out of the total, 167 journals were selected from the DOAJ, 121 journals from Beall's list, and the last 16 were taken from both of them. He submitted a bogus medical paper which was accepted by 157 journals and rejected by 98. According to him, from the remaining 49 journals, 29 of them were abandoned by their creators, while the last 20 had communicated by e-mail saying that the manuscript is still in the process of review.

Bohannon (2013: 61) highlighted that 'the location of a journal's publisher, editor, and bank account are often continents apart. Acceptance was the norm, not the exception. The paper was accepted by journals hosted by industry titans Sage and Elsevier. The paper was accepted by journals published by prestigious academic institutions such as Kobe University in Japan. It was accepted by scholarly society journals. It was utterly inappropriate, Furthermore, Bohannon (2013) was very surprised that $45 \%$ of the publishers listed in DOAJ that completed the review process of the paper, accepted it. support best practices (Berger, 2017). an overview of the resources you analyze while researching used as the main review method. Furthermore, Whittemore and Knafl (2005: 547) define the integrative review as 'the broadest type of research review methods allowing for the sumltaneous inclusion of experimental and non-experimental research in order to more fully understand a phenomenon of als reviews may also combine data from the theoretical as well as empirical literature In addition, integrative reviews incorporate a wide range of purposes: to define concepts, to review theories, to review evidence, and to analyse methodological issues of a particular topic.

The review includes 28 scientific articles on predatory publishers and journals. We searched DOAJ and Google Scholar with the erms predatory publisher and predatory journal. Selected articles for analysis belong to the period 2013-2018. Thus, to investigate the ways of identifying predatory journals, we have it, we have presented the main findings in the form of lists, methods, and tools, which are valid in the academic circles developed a guiding algorithm for evaluating publishers and journals.

\section{RESULTS}

Academics that mainly carry out their scientific activity outside main industrial states are faced with tough dilemmas for choosing journals to publish. The acceptance of their

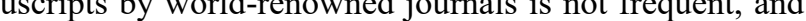
列 fin

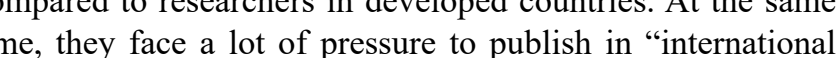
, the a pressure to publish in "inten ost cases, they lack the jecters to pay for publication (Björk, 2017). Rightly Kurt (2018) points out that there is a great need to ralse awareness about

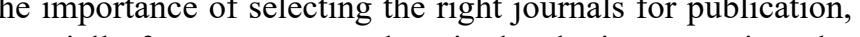
especially for young rescarchers in developing counties who Jalalian and Dadkhah (2015: 82) think that 'developing a list
MATERIALS AND METHODS

This paper is mainly based on the literature review. In line with Fink (2013), the literature review is designed to provide particular topic. More concretely, an integrative review was nd easily accessible form new researchers. Also, we have 政, predatory publishers trying to look like international scientific

This tool can be downloaded from the following link: https://digitalcommons.lmu.edu/librarian pubs/40/.

the Scholarly Publishing and Academic Resources Coalition (SPARC) and its partner affiliates, continue to provide critically-needed guidance and resources. 
"GOOD JOURNALS" is a far better and more effective way to achieve that goal than publishing lists of "BAD JOURNALS"
(That refers to the questionable journals), "HIJACKED (That refers to the questionable journals), "HIJACKED
JOURNALS" (that refers to the legitimate journals that their online identity is stolen by cybercriminals), and "FAKE PUBLISHERS" (that refers to the publishers of journals that are not registered officially by real persons or companies). Developing lists of quality journals and evaluating the quality of the academic journals on each of the main aspects of scientific publishing, such as the editorial workflow, peer-review proces, aspects, is our current concern and the topic of our research.' There are several lists, methods, and tools to identify legitim publishers and journals as well as vice versa. In the following we will examine and discuss the main black and whitelists, proceeding further with other method.

\section{Blacklists}

According to Beall (2013), a blacklist is easier to compose and keep than a whitelisted one. Also, it has more up-to-date information than a whitelist.

\section{Beall's list}

With the rise of open access and the movement to publish articles only online, the number of publishers and journals using the open-access model also increased (Richtig et al, a librarian, and researcher at the University of Colorado, Denver. It was 2008, and Beall began to notice an influx of emails from new journals, asking him to send articles or join their editorial boards (Butler, 2013). In response to this phenomenon, he decided to devote himself to these ghosts and after a period of effort and work he created a list of predatory publishers and journals, which today is known as the Beall's list.

Quek and Teo (2018) mentioned that in 2010, Beall published his first list of "potential, possible, or probable predatory scholarly open-access publishers.' He published the

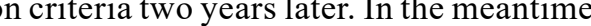
he published other works on the subject. In January 2017 because of legal pressure (Umlauf and Mochizuki, 2018), Beall deleted the list of potential predatory publishers from his blog.

Beall's articles have been widely criticized, includin evaluation bias criteria and the lack of direct contact with publishers, to better understand their processes before blacklisting them (Quek and Teo 2018). However, there is an archived version of the Beall's list at webpage hitps:// archive.fo/6EByy. The list contains 1,162 predatory publishers and 1,310 standalone journals. Beall's list of criteria includes five main issues: 'editor and staff, busines. management, integrity, poor journal standards/practices and other.

Despite the critics, Beall's list is the most known blacklis and also most used and discussed among academics (Bohannon, 2013; Butler, 2013; Xia, 2015; Xia et al, 2015; Shen and Björk, 2015; Danevska et al, 2016; Memon, 2016;
Wallance and Perri, 2018; Björk, 2017; Bagues, Sylos-

Labini and Zinovyeva, 2017; Laine and Winker, 2017; Berger, 2017; Frandsen, 2017; Kurt, 2018; Ritching et al, 2018. Quek Strielkowski, 2018).

As Umlauf and Mochizuki (2018) point out, Beall's criteria for completing these lists were not research-based but they were based on library science standards.

Bagues et al (2017) investigated the degree of publications of Italian authors in "predatory" journals and their motivations. They found that in 2012, the last year in their sample, about $5 \%$ of all papers by Italian economists and management academics in journals (English-language) were published in predatory journals $(6,000$ out of 1.8 million publications). Wallace and Perri (2018) examined the degree of publications in economics predatory journals. They analyzed the articles from selected data for authors
from ninety different countries, although it turned out that only eight countries accounted for almost $50 \%$ of the articles and authors. They used Beall's lists to identify predatory journals and publishers included in the Research Papers in
jols Economics archives (RePEc) and found that a huge number of researchers who are in the RePEc top 5\%, have also published in predatory journals in 2015 .

It should also be noted that the results of Bohannon (2013) point out that Beall has been successful in identifying poor quality publishers, as $82 \%$ of publishers on its list who 作

\section{Cabell's blacklist}

Cabell's blacklist emerged in 2017 when the Beall's blog was closed. This list is presented by its creators, Cabell's, the scholarly analytics company from Beaumont, Texas, as the "the only blacklist of deceptive and predatory academic journals." Today, this list contains more than 4,000 regular journals and (Strielkowski, 2018).

Beall's List was accessible free of charge, and everybody could consult it any time. Meanwhile, Cabell demands enormous payments for their blacklist. As stated by Cabell's, 'the 1-year Dest purchased for a $\$ 1500$ addWest with the purchase of at least 1 more discipline on the Whitelist (ranging from $\$ 1000$ to $\$ 3600$ for 1 set).' Regrettably, Cot

\section{Whitelists}

Academics have sought a credible whitelist to identify egitimate acadenic jounals as an allertave to the blacklist (Umlauf and Mochizaki, 2018). Indeed, white lists have existed much earlier than blacklists. The most peptar whistists are avallable in the Web or Scicnce (WoS) and Scopus databases. Also, several other databases are 列 to. There are other databases that archive academic papers from varous world-wide journals. Or these, some are closely disers so a contain scientific field. In the fowing, we will discuss some of the most credible and highly appreciated databases in the academic world.

According to the official website, Web of Science is 'the
ERIES Journal volume 13 issue 3 world's leading citation database, with multidisciplinary information from over 18,000 high impact journals, over 180,000 conference proceedings, and over 80,000 books from
around the world. With over 100 years of comprehensive coverage and more than one billion cited reference connections, you can search with confidence and explore the complete network of citations underpinning the significant research in any field' (Web of Science, 2018). It is managed by Clarivate Analytics.

In addition to many other products available, Web of Science provides for free The Master Journal List which includes all journal titles covered in it and it is updated bi-monthly (six times a year)

This list is considered a whitelist, so it should be the first whitelist taken into consideration by researchers and scholars to select journals for publication. It is worth noting that besides the possibility of downloading it, there is also the option of online search to see if a certain journal is indexed or not in the Web of Science. This search can be done by
writing the full name of the journal (without errors) or the ISSN number (print or online).

Scopus is considered the second database at world level, i.e. after the Web of Science. Although on their official website it is presented as 'the largest abstract and citation database of peer-reviewed literature: scientific journals, books and conference proceedings.' It is a registered trademark of Elsevier Company and dates back to 1970 . It has over 5,000 publishers, 22,800 serial titles, and 150,000 books and has about 1.4 billion cited references from the early start (Scopus, 2018b).

Scopus also has a database that includes indexed journal titles, but to access it easily you need to be registered with Scopus. In addition, Elsevier offers access for free to the updated Scopus list on the official website, which is an Excel workbook, but usually, you cannot find it easily. This list can be accessed through the following link: https://www.elsevier. com/solutions/scopus/how-scopus-works/content. As well, Scopus always updates the list of journal titles that have been removed from its database for various reasons and this lis can be found in the same place.

We have analyzed the second list, that is, with the titles removed in order to find the reason why such titles have been removed. This list currently contains 424 titles. Of these, 289 (about 68\%) have been removed due to publication concerns, 114 (about 27\%) have been removed because they did not meet any of Scopus set metrics and benchmarks. The remaining of 21 (about $5 \%$ ) are identified by the so-called "radar" tool, which means that they have undergone rapid unexplained changes (Scopus, 2018a).

Since the predatory journals are on the rise, Scopus has taken rigorous measures and is constantly re-evaluating the titles listed to ensure titles continue to meet high-quality standards. Each year, about 3,500 new titles are proposed to be added in Scopus, but roughly $33 \%$ of these titles fulfil the minimum criteria (Scopus, 2018a). Therefore, they suggest that in addition to their whitelist, the list of removed titles should also be checked.

The Directory of Open Access Journals (DOAJ) was

ERIES Journal volume 13 issue 3 established 10 years ago by a library scientist at Lund University in Sweden, known as Lars Bjørnshauge (Bohannon, (Berger 2017). This continues to be the most important whitelist (Berger, 2017). The DOAJ started with 300 open access journals and today contains $12,152 \mathrm{OA}$ journals including all fields of science as technology, medicine, social
humanities from 128 countries across the world.

Laine and Winker (2017) emphasize that DOAJ is not an allinclusive list of all genuine $\mathrm{OA}$ journals. If a journal is not listed on it, it should not be supposed that it is illegitimate or fictitious. It could be a journal that has not made a request to be included in DOAJ or there is not enough allocated fund to fulfil all of its conditions. Contrariwise, joining DOAJ does not assure great value - DOAJ has a standard tool for its users, it seeks to warn them if they see a journal with doubtful

practices on its list.
According to Berger (2017: 208), 'the most significant result of the sting was that DOAJ, which continues to be the most important whitelist, required all its listed journals to reapply using a rigorous vetting system. As of December 2016 ,
DOAJ accepted 3,700 journals, rejected 6,500 applications. removed 1,450 journals and delisted 2,850 journals for not re-applying to stay indexed.

Memon (2016) sheds light that articles published in predatory journals are likewise apparent on ResearchGate as that of trustworthy journals. According to him, ResearchGate uploaded. Maybe this is the rilter the content of the papers from predatory journals on ResearchGate.

\section{"Think. Check. Submit” approach}

As cited by Forrester, Björk and Tenopir (2017: 281), many studies over the last two decades have examined that decision process, and it is a complex array of from subg criteria, including, among other factors, time potential audience, fees, impact factor, and perceptions of prestige' (Björk and Holmström, 2006; Björk and Öörni, 2009; Coonin and Younce, 2010; Jamali et al, 2014; Mabe, 2009; Mabe and Amin, 2002; Mabe and Mulligan, 2011; Rowlands and Nicholas, 2005; Tenopir et al, 2011, 2016).' On the other hand, although there are many debates and discussions in academic circles regarding predatory pablishers, the ovidence is obvious that they exist in the we we need to be very careful when accepting invitations to we cerser. Teo, 2018). Kurt (2018) points out that the pressure to pablish of . Kanses (20searchers to fall prey to advertising aned by predatory journals because they do not analyze the for pulit of the journal at all before sending the mascript

According to the official website, "Think. Check. Submit." is "a campaign to help researchers to identify that jown sor the research. It is a simple checklist that researchers can use to assess the credentials of a journal or publisher. The campaign has been produced 
with the support of a coalition from across scholarly communications $^{3}$ in response to discussions about deceptive publishing.

The key questions of this approach include (Think, Check, Submit, 2018):

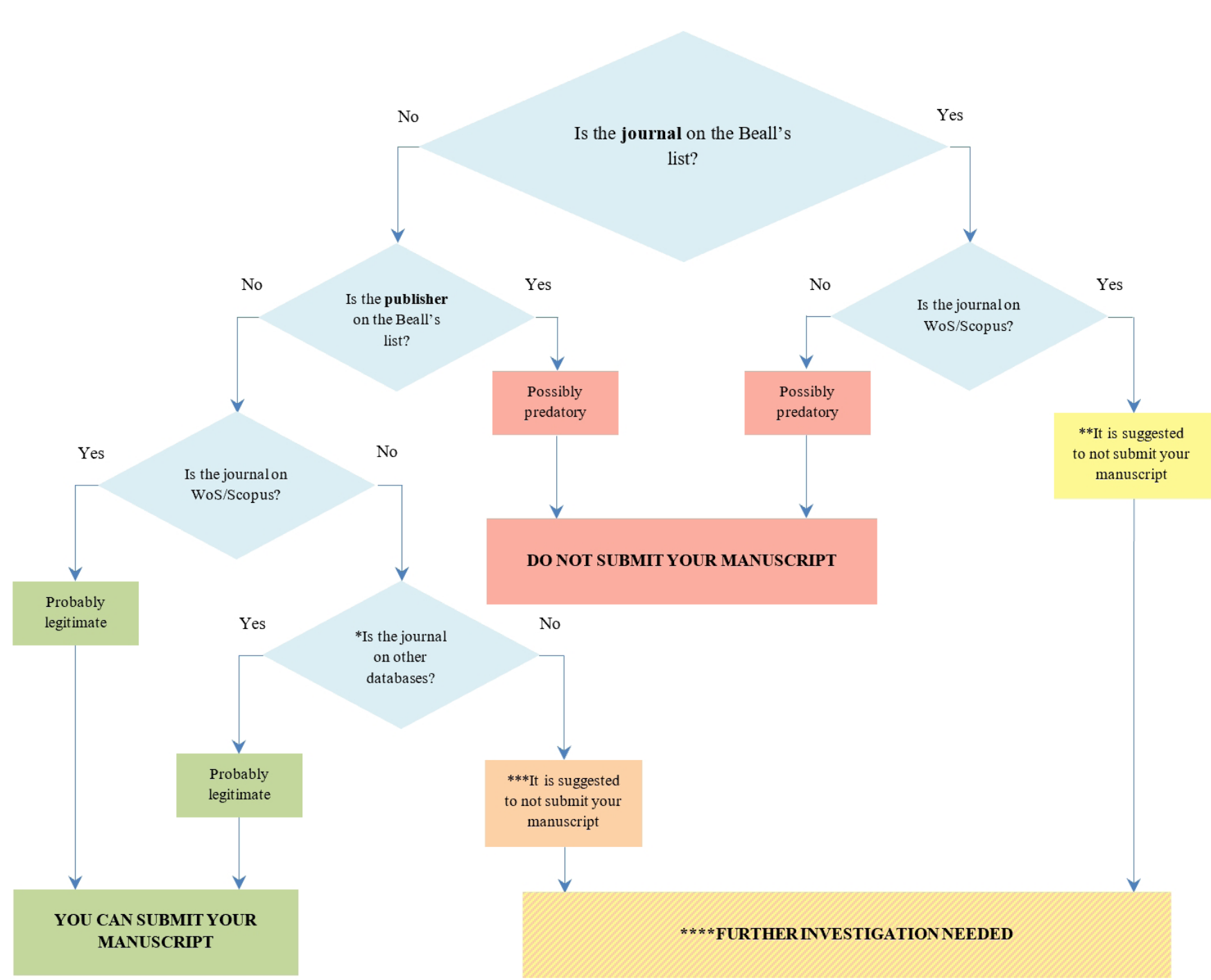

* With other databases, we mean all other reliable academic databases.

** Since the predatory journals are on the rise, Scopus has taken rigorous measures and is constantly re-evaluating the titles listed to ensure titles continue to meet high quality standards. Thus, if a journal is on the Beall's list
submit the manuscript since such journal in the near future may be removed by them.

*** If a journal is not on WoS/Scopus or in any other reliable academic databases, it is suggested not to submit the manuscript.

**** It is recommended to visit websites of journals and analyze them according to the characteristics given by many authors on predatory journals/publishers. This review should also include analyzing the published papers in these journals. The more such features are present, the more you should hesitate to submit the manuscript for publication.

\section{Figure 1: Predatory journals evaluation algorithm}

3 Association of Learned \& Professional Society Publishers (ALPSP), BioMed Central, Committee on Publication Ethics (COPE), Directory of Open Access Journals (DOAJ), ISSN International Centre, Ligue des Bibliothèques Européennes de Recherche - Association of European Research Libraries (LIBER), Open Access Scholarly Publishers Association (OASPA), Springer Nature, International Association of STM Publishers (STM), Ubiquity Press
ERIES Journal volume 13 issue 3
We have developed a guiding algorithm for evaluating publishes dend joud a giding algoily for eve the set up by these predatory publishers and journals, often young researchers inadvertently found themselves part of them

As mentioned earlier, the most popular whitlists are avithe

in the Web of Science and Scopus databses. The Web of Science database should be the first whitelist taken into consideration by researchers and scholars to select joun into publication, followed by Scopus.

\section{DISCUSSION}

Predatory journals are a blight on science, and something needs to be done to curtail these unethical publishers (Clark, however, it is difficult to measure. Some studies confirm that the country's regional distribution of publication and authorship is highly skewed and lead by Asian and African researchers (Frandsen, 2017). Whereas, Kurt (2018) think that numerous scholars from developing countries have the impression that western journals will reject them and so they seek alternative
journals for publication. Severin et al (2020: 10) discuss that: 'inexperienced scholars and scholars in developing countries might be more likely to be tricked into believing that they review for a legitimate journal. It is also possible that predatory journals provide an opportunity for marginalized members of the global academic community to survive in the "publish or perish" culture of today's academia.

As we have seen, the "academic pollution" has affected a number of prestigious institutions. Clark (2018) considers that even the most prestigious institutions in the world have been affected, although the cases are few, 9 articles from Harvard University and 11 from Mayo Clinic. Bohannon (2013) found that $45 \%$ of the publishers listed in DOAJ that completed the bogus paper' review process, have accepted it. Fortunately, the "Bohannon Sting" operation resulted in certain noteworthy changes (Berger, 2017). Wallance and Perri (2018) found that in 2015 an unexpected number of scholars who are in the top $5 \%$ in $\mathrm{RePEc}$, have also published in predatory journals.

Beall had only scientific journals as an initial focus. But the same strategies of predatory publishers are being used to organize fake conferences, to deceive academics, to hijack legitimate journals' websites, to offer low-quality science without proper academic values, and to give space to unethical authors. Consequently, these cybercriminals are misusing the necessity of academics and researchers to publish their work. Also, they are getting rich because many dishonorable authors are willing to pay to publish low-quality manuscripts for the purpose of profession advancement (Umlauf and Mochizuki, 2018).

As stated by Richtig et al. (2018: 3), 'Although Beall's list had certain shortcomings, it represented a valuable tool that researchers could use to assess journals on the basis of their credibility, raised awareness about this important issue an provided guidance for other institutions to create their own blacklists.

Academics involved in the staff advancement process should warn and advise young researchers on where to submit their manuscripts for publication. Review committees for academic ent should also be prepared to conduct a serious evalu articles published in predatory or captured jatic (1)

(important scientific work that does no the prough process should not be included in the register of scientific data (Laine and Winker, 2017). Richtig et al (2018) propose that a new system would have to be implemented to identify predatory journals.

Rightly Strielkowski (2018) raises the concern that there no clear recommendation as to what to do with journals hat Beall suspected of having fraudulent practices that are indexed in respected databases such as Web of Science and Scopus. Should the researchers continue to publish on them or should they seek other blacklists and guidelines from ethics or should they seek other blacklists and guidelines from ethics
commissions for publication? If so, who would select such commissions, or who will determine which journals are good and which ones are bad?

According to Memon (2016: 1645), 'ResearchGate has been lenient in its policies and has created a space for predatory journals to enter the website. Some of the journals displaying ake impact factor on their website (previously mentioned) are available in ResearchGate with an impact factor - a misleading point for scientists who rely on ResarchGate.' He also points out (Memon, 2016: 1647) that 'ResearchGate should take serious note of the fact that considerations given to ghost journals and putting them in the row of reliable and quality journals might create an alarming situation in future. This ark side of academic writing should be hampered, before it finds more space and prevails, as it would not only affect the

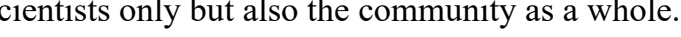

Beall (2016) has proposed some policy changes as follows: he use of the quantity of articles published as a measure of cademic performance should be prohibited by universities and colleges, tesearchers and esteemed journals should not quote articles from predatory journals and academic library databases provich jovide pulishers with services, including those that license

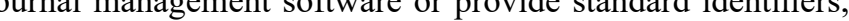
J

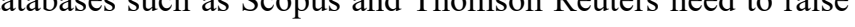
列

ONCLUSION

This paper aims to provide information on recognizing and The consulted the tecent literature and practices of different countries, a do ind pulding algorithm for evaluating journals/ This

and identifying and avoiding publishing in predatory journals. 
Thus, it may be of particular interest to the countries that face This paper is mainly based on the literature review. In the future, the same academic problems. There are a number of other the empirical aspect should be included as well. Hence, the rate limitations be taken into account in future research.

josides this, the reasons and motives of publication in these journals should be examined.

\section{REFERENCES}

Bagues, M., Sylos-Labini, M. and Zinovyeva, N. (2018) 'A Jalalian, M., and Dadkhah, M. (2015) 'The full story of 90 hijacked journals from August 2011 to June [Online], Available: http://hdl.handle.net/10419/171025 [11 May 2020].

Beall, J. (2010). "Predatory" open-access scholarly publishers. The Charleston Advisor, Vol. 11, No. 4, pp. 10-17.

Beall, J. (2013) 'Predatory publishing is just one of the consequences of gold open access', Learned Publishing,
26, No. 2, pp.79-84. htps://doi.org/10.1087/20130203

Beall, J. (2016) 'Ban predators from the scientific
record', Nature, Vol. 534, No. 7607, pp. 326-327. https:// doi.org/10.1038/534326a

Berger, M. (2017) 'Everything you ever wanted to know about predatory publishing but were afraid to ask', ACRL 2017 Conference, Baltimore, Maryland, pp. 206-21

Björk, B.C. (2017) 'Journal portals-an important infrastructure for non-commercial scholarly open access publishing, Online Information Review, Vol. 41, No. 5, pp. 643-654 ittps://doi.org/10.1108/OIR-03-2016-0088

Bohannon, J. (2013) 'Who's afraid of peer review?', Science, Vol. 342, No. 6154, pp. 60-65. https://doi.org/10.112

Bolick, J., Emmett, A., Greenberg, M. L., Rosenblum, B., and Peterson, A. T. (2017) 'How open access is crucial to the Vol. 81, No , 4, pp. 564-566, https://doi org/10 1002/ jwmg.21216

Butler, D. (2013) 'The dark side of publishing', Nature, Vol. 495, No. 7442 , pp. 433-435. https://doi.org/10.1038/495433a

Clark, J. (2018) 'Letter to the editor-predatory journals: Bad for all but especially authors from low and middle income 184-185. https://doi.org/10.20344/amp.10489

Danevska, L., Spiroski, M., Donev, D., Pop-Jordanova, N. and Polenakovic, M. (2016) 'How to recognize and avoid potential, possible, or probable predatory open-acces publishers, standalone, and hijacked journals', Prilozi, Vol. 37, No. 2-3, pp. 5-13. https://doi.org/10.151 A. (2013) Conduct

Fink, A. (2013) Conducting research literature reviews: From
the Internet to paper, Thousand Oaks: Sage Publications the Internet to paper, Mhousand Oaks. Sage Publications.

Forrester, A., Björk, B. C., and Tenopir, C. (2017) 'New web services that help authors choose journals', Learned org/10.1002/leap. 111

Frandsen, T. F. (2017) 'Are predatory journals undermining the credibility of science? A bibliometric analysis of
citers', Scientometrics, Vol. 113, No. 3, pp. 1513-1528. https://doi.org/10.1007/s11192-017-2520-x

Kozak, M., and Hartley, J. (2013) 'Publication fees for open access journals: Different disciplines-different methods', Journal of the American Society for Information Science and Technology, Vol. 64, No. 12, pp. 2591-2594.

Kurt, S. (2018) 'Why do authors publish in predatory journals?', Learned Publishing, Vol. 31 ,

M. A. (2017) 'Identifying predatory or pseudo-journals', Biochemia Medica, vol. 27, No. 2, p 285-291. https://doi.org/10.11613/BM.2017.03

Memon, A. R. (2016) 'ResearchGate is no longer reliable: leniency towards ghost journals may decrease its impact on the scientific community", Journal of Pakistan Medical

Quek, H. C., and Teo, E. K. (2018) 'Predatory publishing; pressures, promotions and perils', Proceedings of
Singapore Healthcare, Vol. 27, No. 1, pp. 3-5. https://doi. org/10.1177/2010105817749602

Preston, A. (2020) 'Solving the Mystery of Peer Review for com/webofsciencegroup/article/solving-the-mystery-ofpeer-review-for-predatory-journals/ [4 July 2020].

Rele, Sh., Kennedy, M., and Blas, N. (2017), Journal Evaluation Tool. LMU Librarian Publications \& Presentations, [Online], Available: http://digitalcommons.lmu.edu/ librarian_pubs/40 [10 Jun 2020].

Richtig, G., Berger, M., Lange-Asschenfeldt, B., Aberer, W., and Richtig, E. (2018) 'Problems and challenges of Dermatology and Venereology, Vol 32 https://dol.org/10.111/jdv.15039

copus (2018a) The Scopus solution to predatory journals, Sem0417 170417 0930 Steiging. ndf [27 Sep 2018]?

Scopus (2018b), [Online], Available: https://www.scopus.com/ [27 Sep 2018].

Severin, A., Strinzel, M., Egger, M., Domingo, M., and Barros, T. F. (2020) Who reviews for predatory journals? Available: https://www biorxiv. oro/content/biorviv/, early/2020/03/11/2020.03.09.983155.full.pdf [5 July 2020].

Shamseer, L., Moher, D., Maduekwe, O., Turner, L., Barbour, V., Burch, R., Clark, J., Galipeau, J., Roberts, J. and Shea, B.J. (2017) Potential predatory and legitimate biomedical comparison', BMC Medicine, Vol. 15, No. 1, 28. https://
doi.org/10.1186/s12916-017-0785-9

Shen, C., and Björk, B. C. (2015), 'Predatory'open access: a longitudinal study of article volumes and marke https://doi org/10.1186/s12916-015-0469-2

Strielkowski, W. (2018) 'Setting new publishing standards after the Beall's list', The International Journal of Occupational https://doi.org/10.15171/ijoem.2018.1314

The Directory of Open Access Journals (2018), [Online], Available: https://doaj.org [24 Sep 2018].

Think. Check. Submit (2018), [Online], Available: http:// thinkchecksubmit.org $/$ [23 Sep 2018]. http://dx.doi.org/10.1002/asi.22972 Predatory Journals', [Online], Available: https://clarivate. predatory journals, Journal of the European Academy of journals: can you tell the difference? A cross-sectional 